\title{
Visceral adiposity, not abdominal subcutaneous fat area, is associated with high blood pressure in Japanese men: the Ohtori study
}

\author{
Hideo Koh ${ }^{1}$, Tomoshige Hayashi ${ }^{1,2}$, Kyoko Kogawa Sato ${ }^{1}$, Nobuko Harita ${ }^{1}$, Isseki Maeda ${ }^{1}$, Yoshiki Nishizawa ${ }^{3}$, \\ Ginji Endo ${ }^{1}$, Wilfred Y Fujimoto ${ }^{4}$, Edward J Boyko ${ }^{2,4}$ and Yonezo Hikita ${ }^{1,5}$
}

Visceral adiposity is considered to have a key role in cardiometabolic diseases. The purpose of this study is to investigate cross-sectionally the association between intra-abdominal fat area (IAFA) measured by computed tomography (CT) and high blood pressure independent of abdominal subcutaneous fat area (ASFA) and insulin resistance. Study participants included 624 Japanese men not taking oral hypoglycemic medications or insulin. Abdominal, thoracic and thigh fat areas were measured by CT. Total fat area (TFA) was calculated as the sum of abdominal, thoracic and thigh fat area. Total subcutaneous fat area (TSFA) was defined as TFA minus IAFA. Hypertension and high normal blood pressure were defined using the 1999 criteria of the World Health Organization. Multiple-adjusted odds ratios of hypertension for tertiles of IAFA were 2.64 (95\% confidence interval, 1.35-5.16) for tertile 2, and $5.08(2.48-10.39)$ for tertile 3, compared with tertile 1 after adjusting for age, fasting immunoreactive insulin, diabetes status, ASFA, alcohol consumption, regular physical exercise and smoking habit. IAFA remained significantly associated with hypertension even after adjustment for ASFA, TSFA, TFA, body mass index or waist circumference, and no other measure of regional or total adiposity was associated with the odds of hypertension in models, which included IAFA. Similar results were obtained for the association between IAFA and the prevalence of high normal blood pressure or hypertension. In conclusion, greater visceral adiposity was associated with a higher odds of high blood pressure in Japanese men.

Hypertension Research (2011) 34, 565-572; doi:10.1038/hr.2010.271; published online 13 January 2011

Keywords: computed tomography; epidemiology; high normal blood pressure; visceral adiposity

\section{INTRODUCTION}

Many epidemiological studies have reported the association between central obesity, assessed by waist circumference, the ratio of waist-tohip circumference or the ratio of subscapular-to-triceps skinfold, and cardiometabolic diseases. ${ }^{1-9}$ The association between abdominal fat distribution assessed by surface measurements and hypertension has been inconsistent as reported by several epidemiological studies. ${ }^{3-7}$ These surface measurements cannot distinguish the contribution of visceral fat from that of subcutaneous abdominal fat. Computed tomography $(\mathrm{CT})$ is an alternative approach that allows the precise separation between the visceral and subcutaneous adipose tissue compartments. In particular, visceral adiposity measured by CT has been reported to be associated with insulin resistance and cardiometabolic diseases. ${ }^{10-15}$

Only a few epidemiological studies have examined the association between visceral adiposity directly measured by CT and hypertension, ${ }^{13,14,16,17}$ but the results were inconclusive. In Japanese Amer- icans, the intra-abdominal fat area (IAFA), but not the abdominal subcutaneous fat area (ASFA), was associated with the prevalence and incidence of hypertension. ${ }^{13,14}$ Fox et al. ${ }^{16}$ showed in Caucasians that both visceral and abdominal subcutaneous fat volume were associated with the prevalence of hypertension. On the other hand, Foy et al. ${ }^{17}$ reported in African-American and Hispanic-American men that ASFA, but not IAFA, was associated with the prevalence of hypertension. Oka et al. ${ }^{18}$ showed in native Japanese that both visceral and ASFAs were correlated with systolic and diastolic blood pressure. Differences in ethnicity or adjustment for other potentially confounding variables such as insulin resistance or abdominal subcutaneous fat may explain in part these inconclusive findings. The effect of visceral adiposity on hypertension for Asian populations might be more important than for the other ethnic population because Asians and Asian Americans have been reported to have a lower prevalence of obesity by body mass index compared with Caucasians ${ }^{19,20}$ but a greater degree of visceral adiposity. ${ }^{21}$

${ }^{1}$ Department of Preventive Medicine and Environmental Health, Osaka City University Graduate School of Medicine, Osaka, Japan; ${ }^{2}$ Epidemiologic Research and Information Center, Veterans Affairs Puget Sound Health Care System, Seattle, WA, USA; ${ }^{3}$ Department of Metabolism, Endocrinology, and Molecular Medicine, Osaka City University Graduate School of Medicine, Osaka, Japan; ${ }^{4}$ Department of Medicine, University of Washington, Seattle, WA, USA and ${ }^{5}$ The Ohtori Health Promotion Center, Sakai, Japan

Correspondence: Dr T Hayashi, Department of Preventive Medicine and Environmental Health, Osaka City University Graduate School of Medicine, 1-4-3, Asahi-machi, Abenoku, Osaka 545-8585, Japan.

E-mail: thayashi@med.osaka-cu.ac.jp

Received 9 July 2010; revised 26 October 2010; accepted 16 November 2010; published online 13 January 2011 
Therefore, we cross-sectionally examined whether visceral adiposity measured by CT was associated with an increased odds of the prevalence of hypertension and of high normal blood pressure or hypertension in Japanese men independent of other adipose depots and insulin resistance.

\section{METHODS}

\section{Study subjects}

The Ohtori study. The Ohtori Study is an ongoing cohort investigation designed to examine relationships between body fat distribution and cardiometabolic diseases. Between December 2005 and February 2007, 710 Japanese men (28-76 years old) who visited the Ohtori Health Promotion Center for a medical checkup were enrolled in this study.

For the current analysis, eligible participants consisted of 687 Japanese men not taking oral hypoglycemic medication or insulin. We excluded 29 of the 687 participants because of serum creatinine of $1.5 \mathrm{mg} \mathrm{dl}^{-1}$ or more, undergoing renal disease therapy, history of cardiovascular disease or history of cancer. Another 34 persons missing covariate information were also excluded. The analytic cohort consisted of 624 participants.

\section{Data collection and measurements}

All measurements were made in the Ohtori Health Promotion Center, Sakai, Japan. The protocol for this research was approved by the Human Subjects Review Committee at Osaka City University and signed informed consent was obtained from all the participants. The clinical examination consisted of a medical history; a physical examination; anthropometric measurements; measurements of fasting plasma glucose and immunoreactive insulin levels; measurements of fat areas by CT as described below; and self-administered questionnaires on health-related behaviors. After a 5-min rest in a quiet room, systolic and diastolic blood pressures were measured on the right arm with an automatic sphygmomanometer while the participant was seated (BP-203RV II; Omron Colin, Tokyo, Japan). Spearman's correlation between the former device and a standard mercury sphygmomanometer was 0.973 for diastolic blood pressure and 0.985 for systolic blood pressure in a voluntary sample $(n=60)$. Blood pressure was measured twice at an interval of a few minutes and the subject's blood pressure was defined as the average of the two readings. Blood samples were drawn after an overnight 12-h fast. Plasma glucose was assayed by an automated hexokinase method. The intra- and inter-assay coefficients of variation were 0.8 and $2.0 \%$, respectively. Fasting immunoreactive insulin was measured by a chemiluminescent immunoassay. The intra- and inter-assay coefficients of variation were 2.7 and $3.5 \%$, respectively. Insulin resistance was evaluated by using the homeostasis model assessment-insulin resistance (HOMA IR), calculated as (fasting immunoreactive insulin $\left.\left(\mu \mathrm{U} \mathrm{ml}^{-1}\right)\right) \times\left(\right.$ fasting plasma glucose $\left.\left(\mathrm{mg} \mathrm{dl}^{-1}\right)\right) / 405$ (Matthews et al. $\left.{ }^{22}\right)$. Height and weight were measured in shoeless participants wearing light cloths. We calculated body mass index as weight in kilograms divided by height in meters squared. Waist circumference was measured at the level of the umbilicus while participants were in a standing position.

The questions about usual alcohol consumption included the weekly frequency of alcohol consumption, the type of alcohol beverages and the usual amount consumed per drinking day. The quantity of alcohol consumption was converted to weekly consumed ethanol volume in grams using standard Japanese tables. Regarding regular physical exercise, a detailed questionnaire was administered about the types of leisure-time physical activities they took part in (described as light, moderate or vigorous in accordance with the Centers for Disease Control and Prevention), ${ }^{23}$ their weekly activity frequency and time spent in each activity. Participants were classified as engaging in regular leisuretime physical activity at least once weekly if they reported that they engaged in light or more intense activities at least once weekly. Regarding smoking habits, participants were classified as current smokers, past smokers or nonsmokers.

\section{Evaluation of CT imaging}

All participants were scanned at the end of inspiration in a supine position with their arms extended above their head and their legs extended using an X Lead (Toshiba Medical, Tokyo, Japan) to measure fat areas $\left(\mathrm{cm}^{2}\right)$. In all, 1-cm thick
non-contrast-CT slices were acquired in the chest $(120 \mathrm{kVp}, 100 \mathrm{~mA}$, table speed $10 \mathrm{~mm} \mathrm{~s}^{-1}$, beam pitch $10 \mathrm{~mm}$ and gantry rotation time $1.0 \mathrm{~s}$ ), at the level of the umbilicus $(120 \mathrm{kVp}, 200 \mathrm{~mA}$, beam pitch $10 \mathrm{~mm}$ and gantry rotation time $1.0 \mathrm{~s}$ ), and at mid-thigh midway between the greater trochanter and the superior margin of the patella $(120 \mathrm{kVp}, 200 \mathrm{~mA}$, beam pitch $10 \mathrm{~mm}$ and gantry rotation time $1.0 \mathrm{~s}$ ). The slices at the level of the nipples, the umbilicus and the mid-thighs were used to quantify thoracic subcutaneous fat area, IAFA, ASFA and thigh subcutaneous fat area, respectively. The areas were measured using SliceOmatic 4.2 image analysis software (Tomovision, Montreal, Canada), blinded to all the other measurements of the study participants. We directly estimated visceral adiposity from IAFA at the umbilicus level. This measurement has been reported to have a high correlation with directly ascertained total visceral fat volume measured by using CT or magnetic resonance imaging. ${ }^{24-26}$ Total fat area (TFA) was calculated as the sum of IAFA, thoracic and ASFAs, and twice the right thigh subcutaneous fat area. TFA measured by this method was reported to correlate highly with fat mass measured by hydrodensitometry among Japanese Americans ( $r=0.89-0.94)$ (McNeely et al. $^{27}$ ). Total subcutaneous fat area (TSFA) was defined as TFA minus IAFA. A single observer measured the IAFA and ASFA of all participants, and another measured the thoracic and mid-thigh subcutaneous fat area of all participants. Inter-reader reproducibility was assessed by two independent readers measuring intra-abdominal, abdominal subcutaneous, thoracic subcutaneous and mid-thigh subcutaneous fat areas on a subset of 50 randomly selected participants. The intraclass correlation coefficients for inter-reader comparisons were 0.989 for IAFA, 0.999 for ASFA, 0.996 for thoracic subcutaneous fat area and 0.998 for mid-thigh subcutaneous fat area. In addition, the intraclass correlation coefficients for intra-reader comparisons was 0.999 for IAFA, 0.999 for ASFA, 0.994 for thoracic subcutaneous fat area and 0.999 for mid-thigh subcutaneous fat area.

\section{Diagnosis of hypertension and type 2 diabetes}

Hypertension was defined as systolic blood pressure $\geqslant 140 \mathrm{~mm} \mathrm{Hg}$, diastolic blood pressure $\geqslant 90 \mathrm{~mm} \mathrm{Hg}$ or the use of antihypertensive medications. ${ }^{28} \mathrm{High}$ normal blood pressure was defined as no history of hypertension and systolic blood pressure $\geqslant 130$ and $<140 \mathrm{~mm} \mathrm{Hg}$ or diastolic blood pressure $\geqslant 85$ and $<90 \mathrm{~mm} \mathrm{Hg} .^{28}$ Normotension was defined as no history of hypertension, systolic blood pressure $<130 \mathrm{~mm} \mathrm{Hg}$ and diastolic blood pressure $<85 \mathrm{~mm} \mathrm{Hg} .{ }^{28}$ Type 2 diabetes was defined as a fasting plasma glucose level $\geqslant 126 \mathrm{mg} \mathrm{dl}^{-1}$ or if participants were taking oral hypoglycemic medications or insulin. ${ }^{29}$ Impaired fasting glucose was defined as no history of diabetes and a fasting plasma glucose level $\geqslant 110$ and $<126 \mathrm{mg} \mathrm{dl}^{-1}$. Normal fasting glucose was defined as no history of diabetes and a fasting plasma glucose level $<110 \mathrm{mg} \mathrm{dl}^{-1}$.

\section{Statistical analysis}

Multiple logistic regression analysis was used to estimate the odds ratio for the prevalence of hypertension and of high normal blood pressure or hypertension. Nonlinear effects of continuous independent variables were evaluated using quadratic, square-root and log transformations. The presence of effect modification was tested by the insertion of first-order interaction terms into appropriate regression models. Multicollinearity was assessed by using the variance inflation factor. ${ }^{30} \mathrm{~A}$ variance inflation factor exceeding 10 is regarded as indicating serious multicollinearity, and values $>5.0$ may be a cause for concern. ${ }^{30}$ We calculated the $95 \%$ confidence interval for each odds ratio. All $P$-values were two-tailed. All statistical analyses were performed using the PASW Statistics 17.0 (SPSS, Chicago, IL, USA).

\section{RESULTS}

The characteristics of the study participants are shown in Table 1 . Among the 624 eligible men, we confirmed 148 (24\%) cases of hypertension and $137(22 \%)$ cases of high normal blood pressure. Of all participants with hypertension, $66(44.6 \%)$ were taking antihypertensive medications. Study participants on average were not obese with a mean body mass index of $24.0 \mathrm{~kg} \mathrm{~m}^{-2}$. Participants with high normal blood pressure or hypertension had higher mean values of IAFA and ASFA than those with normotension (Table 1). 
Table 1 Characteristics of study participants

\begin{tabular}{|c|c|c|c|c|}
\hline Characteristics & Total $(\mathrm{n}=624)$ & $\begin{array}{l}\text { Normotension } \\
(n=339)\end{array}$ & $\begin{array}{l}\text { High normal blood pressure } \\
\qquad(\mathrm{n}=137)\end{array}$ & $\begin{array}{l}\text { Hypertension } \\
(n=148)\end{array}$ \\
\hline Age (years) & $49.4 \pm 9.0$ & $47.4 \pm 8.7$ & $48.7 \pm 8.7$ & $54.9 \pm 7.7$ \\
\hline \multicolumn{5}{|l|}{ Metabolic variables } \\
\hline Fasting immunoreactive insulin $\left(\mu \cup \mathrm{ml}^{-1}\right)$ & $5.52 \pm 3.53$ & $4.91 \pm 2.97$ & $6.35 \pm 4.04$ & $6.13 \pm 3.93$ \\
\hline HOMA IR & $1.45 \pm 1.08$ & $1.25 \pm 0.82$ & $1.69 \pm 1.31$ & $1.68 \pm 1.27$ \\
\hline \multicolumn{5}{|l|}{ Diabetes status } \\
\hline Normal fasting glucose (\%) & 81.4 & 87.0 & 81.0 & 68.9 \\
\hline Impaired fasting glucose (\%) & 13.1 & 9.7 & 12.4 & 21.6 \\
\hline Type 2 diabetes $(\%)$ & 5.4 & 3.2 & 6.6 & 9.5 \\
\hline \multicolumn{5}{|l|}{ Adipose variables } \\
\hline Body mass index $\left(\mathrm{kg} \mathrm{m}^{-2}\right)$ & $24.0 \pm 3.1$ & $23.4 \pm 3.0$ & $24.8 \pm 3.1$ & $24.7 \pm 3.0$ \\
\hline Waist circumference $(\mathrm{cm})$ & $86.0 \pm 8.2$ & $84.3 \pm 8.2$ & $87.3 \pm 8.2$ & $88.7 \pm 7.1$ \\
\hline Alcohol consumption (g ethanol per week) & $213.7 \pm 239.7$ & $162.1 \pm 194.3$ & $244.7 \pm 256.0$ & $303.4 \pm 284.4$ \\
\hline Drinking habit $(\%)$ & 82.7 & 79.6 & 84.7 & 87.8 \\
\hline Regular physical exercise (\%) & 47.4 & 45.1 & 46.0 & 54.1 \\
\hline \multicolumn{5}{|l|}{ Smoking habit } \\
\hline Nonsmokers (\%) & 36.4 & 37.2 & 32.1 & 38.5 \\
\hline Past smokers (\%) & 20.7 & 16.2 & 24.8 & 27.0 \\
\hline Current smokers (\%) & 42.9 & 46.6 & 43.1 & 34.5 \\
\hline
\end{tabular}

Abbreviation: HOMA IR, homeostasis model assessment-insulin resistance.

Data are mean \pm s.d. or $\%$.

We stratified participants according to median values of ASFA, TSFA, TFA, body mass index and waist circumference to examine the association between IAFA and the prevalence of hypertension and of high normal blood pressure or hypertension (Table 2). Greater visceral adiposity was associated with higher prevalence of hypertension in all groups (Table 2). On the other hand, after participants were stratified according to IAFA, no measure of ASFA, TSFA, TFA, body mass index or waist circumference was associated with a higher prevalence of hypertension stratified by IAFA tertiles (Table 2). Similar results were obtained for the prevalence of high normal blood pressure or hypertension (Table 2).

In multiple logistic regression analysis, insertion of quadratic, square-root or log transformations of all continuous variables except IAFA into all models did not result in an improvement in fit compared with the linear model. As only IAFA showed a nonlinear association with the prevalence of hypertension in all models, we fit a model by using IAFA categorized into tertiles to account for this nonlinearity (Tables 3 and 4). We examined the significance of the first-order interaction terms in all models of Table 3 between IAFA and the other adipose variables or fasting immunoreactive insulin. None of these interactions was significant. Correlation coefficients between IAFA and ASFA, TSFA, TFA, waist circumference or body mass index were $0.537,0.554,0.744,0.642$ and 0.748 , respectively. Correlation coefficients between fasting immunoreactive insulin or HOMA IR and IAFA, ASFA, TSFA, TFA, waist circumference or body mass index were as follows: for fasting immunoreactive insulin they were $0.460,0.482$, $0.487,0.529,0.534$ and 0.563 , respectively, and for HOMA IR 0.459,
$0.440,0.444,0.494,0.512$ and 0.529 , respectively. Evidence for multicollinearity was absent because the variance inflation factor for independent variables in all models in Tables 3 and 4 was $<4.0$.

We tested several regression models to assess whether body fat distribution was associated with an increased odds of hypertension (Table 3). IAFA was associated with an increased odds of hypertension after adjusting for age, alcohol consumption, regular physical exercise and smoking habit (model 1, Table 3). IAFA was associated with an increased odds of hypertension even after adjusting for age, alcohol consumption, regular physical exercise, smoking habit, ASFA, fasting immunoreactive insulin and diabetes status (model 2, Table 3). Models 3-6 of Table 3 were identical to model 2, with the exception that a different adipose variable was substituted for ASFA. Model 7 was identical to model 2, with the exception that HOMA IR was substituted for fasting immunoreactive insulin. In all of these models, the relationships of IAFA to hypertension did not substantially change (models 1-7, Table 3). Also, neither other measures of regional or total adiposity nor insulin resistance indices emerged as significantly related to hypertension (models 1-7, Table 3).

We tested several regression models to assess whether body fat distribution was associated with an increased odds of high normal blood pressure or hypertension (Table 4). The results of the association between IAFA and high normal blood pressure or hypertension were similar to those between IAFA and hypertension (Table 4). Fasting immunoreactive insulin and HOMA IR were associated with a higher odds of high normal blood pressure or hypertension, but not hypertension (Tables 3 and 4). 
Table 2 Prevalence of hypertension and of high normal blood pressure or hypertension according to intra-abdominal fat area, abdominal subcutaneous fat area, total subcutaneous fat area, total fat area, body mass index and waist circumference

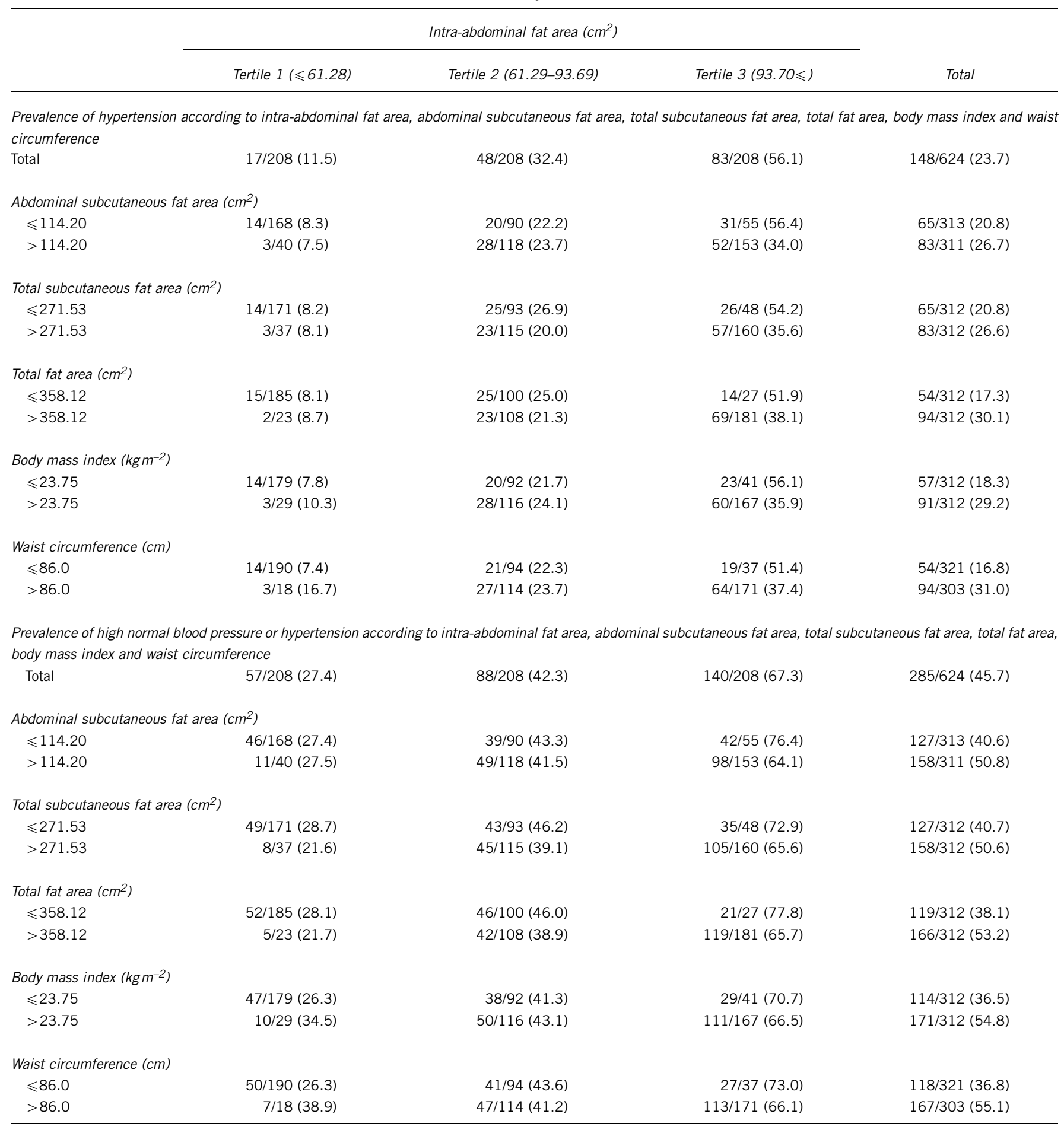

Data are $n(\%)$.

\section{DISCUSSION}

These cross-sectional data demonstrated that greater visceral adiposity was associated with an increased odds of the prevalence of hypertension in Japanese men. These findings were independent of age, fasting immunoreactive insulin, diabetes status, alcohol consumption, regular physical exercise, smoking habit and other measures of regional or total adiposity. On the other hand, no other measure of regional or total adiposity was associated with an increased odds of the prevalence of hypertension after adjusting for IAFA. Similar results were obtained for the association between IAFA and the prevalence of high normal blood pressure or hypertension. 
Table 3 Multivariable models of prevalence of hypertension in relation to intra-abdominal fat area, other adipose depots and insulin resistance indices

\begin{tabular}{|c|c|c|c|c|}
\hline Variables in the models & $\begin{array}{l}\text { Multiple-adjusted } \\
\text { odds ratios }(95 \% \mathrm{Cl})\end{array}$ & P-value & $\begin{array}{l}\text { Further adjustment for fasting insulin } \\
\text { or HOMA IR, odds ratios }(95 \% \mathrm{CI})\end{array}$ & P-value \\
\hline \multicolumn{5}{|l|}{ Model $1^{\mathrm{a}}$} \\
\hline Tertile $1(-61.28)$ & 1.00 (reference) & & - & - \\
\hline Tertile 2 (61.29-93.69) & $2.73(1.46-5.10)$ & 0.002 & - & - \\
\hline Tertile 3 (93.70-) & $5.50(3.01-10.05)$ & $<0.001$ & - & - \\
\hline \multicolumn{5}{|l|}{ Intra-abdominal fat area } \\
\hline Tertile $1(-61.28)$ & 1.00 (reference) & & 1.00 (reference) & \\
\hline Tertile 2 (61.29-93.69) & $2.68(1.38-5.23)$ & 0.004 & $2.64(1.35-5.16)$ & 0.004 \\
\hline Tertile 3 (93.70-) & $5.28(2.61-10.68)$ & $<0.001$ & $5.08(2.48-10.39)$ & $<0.001$ \\
\hline Abdominal subcutaneous fat area & $0.99(0.76-1.29)$ & 0.934 & $0.96(0.73-1.27)$ & 0.787 \\
\hline Fasting immunoreactive insulin & - & - & $1.08(0.85-1.38)$ & 0.522 \\
\hline
\end{tabular}

Model 3: same variables as model 2, except total subcutaneous fat area is substituted for abdominal subcutaneous fat areac

Intra-abdominal fat area

Tertile $1(-61.28)$

Tertile 2 (61.29-93.69)

Tertile 3 (93.70-)

Total subcutaneous fat area

Fasting immunoreactive insulin

$\begin{array}{lr}1.00 \text { (reference) } & \\ 2.90(1.48-5.66) & 0.002 \\ 5.97(2.90-12.28) & <0.001 \\ 0.90(0.69-1.19) & 0.475\end{array}$

$0.90(0.69-1.19) \quad 0.475$

1.00 (reference)

$2.84(1.45-5.57)$

0.002

$5.69(2.74-11.83)$

$<0.001$

$0.87(0.65-1.17)$

0.355

$1.11(0.87-1.42)$

0.403

Model 4: same variables as model 2, except total fat area is substituted for abdominal subcutaneous fat area Intra-abdominal fat area

Tertile $1(-61.28)$

Tertile 2 (61.29-93.69)

1.00 (reference)

Tertile 3 (93.70-)

$2.86(1.43-5.73) \quad 0.003$

$<0.001$

Total fat area

$5.94(2.62-13.47)$

$<0.001$
0.632

Fasting immunoreactive insulin

1.00 (reference)

$2.84(1.42-5.71)$

0.003

$5.83(2.56-13.28)$

$0.89(0.64-1.24)$

$1.10(0.86-1.41)$

0.483

0.434

Model 5: same variables as model 2, except body mass index is substituted for abdominal subcutaneous fat area Intra-abdominal fat area

Tertile $1(-61.28)$

Tertile 2 (61.29-93.69)

Tertile 3 (93.70-)

Body mass index

Fasting immunoreactive insulin

$\begin{array}{lr}1.00 \text { (reference) } & \\ 2.76(1.41-5.41) & 0.003 \\ 5.54(2.66-11.54) & <0.001 \\ 0.96(0.73-1.26) & 0.761\end{array}$

-
1.00 (reference)

$2.74(1.40-5.38) \quad 0.003$

$5.41(2.58-11.32) \quad<0.001$

$0.91(0.68-1.23) \quad 0.555$

$1.11(0.86-1.43) \quad 0.439$

Model 6: same variables as model 2, except waist circumference is substituted for abdominal subcutaneous fat area Intra-abdominal fat area

$\begin{array}{llr}\text { Tertile } 1 \text { (-61.28) } & 1.00 \text { (reference) } \\ \text { Tertile } 2 \text { (61.29-93.69) } & 2.76(1.38-5.56) & 0.004 \\ \text { Tertile } 3(93.70-) & 5.54(2.52-12.19) & <0.001 \\ \text { Waist circumference } & 0.96(0.71-1.31) & 0.802 \\ \text { Fasting immunoreactive insulin } & - & -\end{array}$

1.00 (reference)

$2.77(1.37-5.56)$

0.004

$5.46(2.48-12.06) \quad<0.001$

$0.92(0.66-1.28) \quad 0.617$

Fasting immunoreactive insulin

$1.10(0.85-1.41)$

0.466

Model 7: same variables as model 2, except HOMA IR is substituted for fasting immunoreactive insulin ${ }^{\mathrm{d}}$

Intra-abdominal fat area

Tertile $1(-61.28)$

Tertile 2 (61.29-93.69)

Tertile 3 (93.70-)

Abdominal subcutaneous fat area

HOMA IR

$\begin{array}{ll}- & - \\ - & - \\ - & -\end{array}$

-
-
-

1.00 (reference)

2.67 (1.37-5.21)

0.004

$5.22(2.56-10.62)$

$<0.001$

$0.98(0.74-1.29)$

0.873

$1.03(0.80-1.33)$

0.793

Abbreviations: $\mathrm{Cl}$, confidence interval; HOMA IR, homeostasis model assessment-insulin resistance.

Odds ratios for continuous variables reflect a 1-SD-magnitude increase.

a Model 1 was adjusted for age, alcohol consumption, regular physical exercise and smoking habit (nonsmokers, past smokers and current smokers).

bModel 2 includes age, alcohol consumption, regular physical exercise and smoking habit (nonsmokers, past smokers and current smokers) in addition to all variables shown in model 2 of the Table 3.

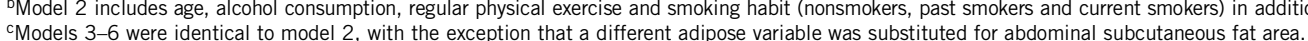

dModel 7 was identical to model 2, with the exception that HOMA IR was substituted for fasting immunoreactive insulin. 
Table 4 Multivariable models of high normal blood pressure or hypertension in relation to intra-abdominal fat area, other adipose depots and insulin resistance indices

\begin{tabular}{|c|c|c|c|c|}
\hline Variables in the models & $\begin{array}{l}\text { Multiple-adjusted odds } \\
\quad \text { ratios }(95 \% \mathrm{Cl})\end{array}$ & P-value & $\begin{array}{c}\text { Further adjustment for fasting insulin } \\
\text { or HOMA IR, odds ratios }(95 \% \mathrm{Cl})\end{array}$ & P-value \\
\hline \multicolumn{5}{|l|}{ Model $1^{\mathrm{a}}$} \\
\hline \multicolumn{5}{|l|}{ Intra-abdominal fat area } \\
\hline Tertile $1(-61.28)$ & 1.00 (reference) & & - & - \\
\hline Tertile 2 (61.29-93.69) & $1.71(1.11-2.64)$ & 0.016 & - & - \\
\hline Tertile 3 (93.70-) & $4.48(2.87-7.00)$ & $<0.001$ & - & - \\
\hline \multicolumn{5}{|l|}{ Model $2^{\mathrm{b}}$} \\
\hline \multicolumn{5}{|l|}{ Intra-abdominal fat area } \\
\hline Tertile $1(-61.28)$ & 1.00 (reference) & & 1.00 (reference) & \\
\hline Tertile 2 (61.29-93.69) & $1.50(0.93-2.44)$ & 0.100 & $1.41(0.86-2.30)$ & 0.170 \\
\hline Tertile 3 (93.70-) & $3.70(2.14-6.42)$ & $<0.001$ & $3.20(1.82-5.61)$ & $<0.001$ \\
\hline Abdominal subcutaneous fat area & $1.12(0.90-1.40)$ & 0.305 & $1.01(0.80-1.28)$ & 0.934 \\
\hline Fasting immunoreactive insulin & - & - & $1.37(1.09-1.71)$ & 0.007 \\
\hline \multicolumn{5}{|l|}{ Diabetes status } \\
\hline Normal fasting glucose & 1.00 (reference) & & 1.00 (reference) & \\
\hline Impaired fasting glucose & $1.04(0.61-1.79)$ & 0.878 & $0.90(0.52-1.57)$ & 0.707 \\
\hline Type 2 diabetes & $1.76(0.77-4.01)$ & 0.181 & $1.46(0.62-3.43)$ & 0.382 \\
\hline \multicolumn{5}{|c|}{ Model 3: same variables as model 2, except total subcutaneous fat area is substituted for abdominal subcutaneous fat areac } \\
\hline \multicolumn{5}{|c|}{ Intra-abdominal fat area } \\
\hline Tertile $1(-61.28)$ & 1.00 (reference) & & 1.00 (reference) & \\
\hline Tertile 2 (61.29-93.69) & $1.62(1.00-2.64)$ & 0.051 & $1.52(0.93-2.48)$ & 0.097 \\
\hline Tertile 3 (93.70-) & $4.13(2.35-7.29)$ & $<0.001$ & $3.57(2.01-6.36)$ & $<0.001$ \\
\hline Total subcutaneous fat area & $1.04(0.83-1.30)$ & 0.763 & $0.92(0.72-1.17)$ & 0.492 \\
\hline Fasting immunoreactive insulin & - & - & $1.41(1.12-1.77)$ & 0.003 \\
\hline \multicolumn{2}{|c|}{ Intra-abdominal fat area } & & & \\
\hline Tertile $1(-61.28)$ & 1.00 (reference) & & 1.00 (reference) & \\
\hline Tertile 2 (61.29-93.69) & $1.58(0.94-2.64)$ & 0.082 & $1.53(0.91-2.57)$ & 0.106 \\
\hline Tertile 3 (93.70-) & $3.91(2.03-7.54)$ & $<0.001$ & $3.69(1.90-7.15)$ & $<0.001$ \\
\hline Total fat area & $1.06(0.82-1.38)$ & 0.658 & $0.92(0.70-1.21)$ & 0.548 \\
\hline Fasting immunoreactive insulin & - & - & $1.40(1.12-1.77)$ & 0.004 \\
\hline \multicolumn{5}{|c|}{ Model 5: same variables as model 2, except body mass index is substituted for abdominal subcutaneous fat areac } \\
\hline \multicolumn{5}{|c|}{ Intra-abdominal fat area } \\
\hline Tertile $1(-61.28)$ & 1.00 (reference) & & 1.00 (reference) & \\
\hline Tertile 2 (61.29-93.69) & $1.32(0.81-2.16)$ & 0.270 & $1.29(0.79-2.12)$ & 0.308 \\
\hline Tertile 3 (93.70-) & $2.94(1.65-5.24)$ & $<0.001$ & $2.78(1.55-4.97)$ & 0.001 \\
\hline Body mass index & $1.29(1.02-1.63)$ & 0.032 & $1.14(0.88-1.47)$ & 0.326 \\
\hline Fasting immunoreactive insulin & - & - & $1.30(1.03-1.65)$ & 0.029 \\
\hline \multicolumn{5}{|c|}{ Model 6: same variables as model 2, except waist circumference is substituted for abdominal subcutaneous fat areac } \\
\hline \multicolumn{5}{|c|}{ Intra-abdominal fat area } \\
\hline Tertile $1(-61.28)$ & 1.00 (reference) & & 1.00 (reference) & \\
\hline Tertile 2 (61.29-93.69) & $1.51(0.90-2.53)$ & 0.119 & $1.49(0.89-2.51)$ & 0.134 \\
\hline Tertile 3 (93.70-) & $3.68(1.96-6.90)$ & $<0.001$ & $3.47(1.84-6.54)$ & $<0.001$ \\
\hline Waist circumference & $1.10(0.86-1.42)$ & 0.448 & $0.95(0.72-1.25)$ & 0.718 \\
\hline Fasting immunoreactive insulin & - & - & $1.39(1.10-1.75)$ & 0.005 \\
\hline \multicolumn{5}{|c|}{ Model 7: same variables as model 2, except HOMA IR is substituted for fasting immunoreactive insulin ${ }^{\mathrm{d}}$} \\
\hline \multicolumn{5}{|c|}{ Intra-abdominal fat area } \\
\hline Tertile $1(-61.28)$ & - & - & 1.00 (reference) & \\
\hline Tertile 2 (61.29-93.69) & - & - & $1.43(0.87-2.33)$ & 0.157 \\
\hline Tertile 3 (93.70-) & - & - & $3.25(1.85-5.70)$ & $<0.001$ \\
\hline Abdominal subcutaneous fat area & - & - & $1.02(0.81-1.29)$ & 0.872 \\
\hline HOMA IR & - & - & $1.39(1.07-1.79)$ & 0.014 \\
\hline
\end{tabular}

Abbreviations: $\mathrm{Cl}$, confidence interval; HOMA IR, homeostasis model assessment-insulin resistance.

Odds ratios for continuous variables reflect a 1-SD-magnitude increase.

aModel 1 was adjusted for age, alcohol consumption, regular physical exercise and smoking habit (nonsmokers, past smokers and current smokers).

bModel 2 includes age, alcohol consumption, regular physical exercise and smoking habit (nonsmokers, past smokers and current smokers) in addition to all variables shown in model 2 of the Table 4.

cModels 3 to 6 were identical to model 2, with the exception that a different adipose variable was substituted for abdominal subcutaneous fat area.

dModel 7 was identical to model 2, with the exception that HOMA IR was substituted for fasting immunoreactive insulin. 
Only limited cross-sectional studies and only one prospective study have investigated associations between CT-measured visceral adiposity and hypertension. ${ }^{13,14,16,17}$ In 1995 , it was reported in the Japanese Americans Community Diabetes Study that the effects of visceral adiposity on blood pressure were of statistical or borderline statistical significance in both second- and third-generation Japanese Americans, but after further adjustment for body mass index, these associations were diminished in the younger generation. ${ }^{31}$ In 2003 , it was reported in cross-sectional data from the same population that greater visceral adiposity was associated with a higher prevalence of hypertension independent of other measures of total or regional adiposity and fasting plasma insulin. ${ }^{13}$ The reason for these different results was described to be partly because of the fact that in the earlier report, participants taking antihypertensive medication or having type 2 diabetes were not included, which by possibly truncating the upper range for blood pressure may have underestimated these relationships. ${ }^{13,14}$ A subsequent prospective analysis from the same cohort showed that greater IAFA, but not ASFA, was associated with the incidence of hypertension after adjustment for fasting plasma insulin. ${ }^{14}$ Fox et al. ${ }^{16}$ showed in the Framingham Heart Study that among Caucasians, both visceral and abdominal subcutaneous fat volumes were associated with prevalence of hypertension. They did not report whether visceral fat volume was associated with the prevalence of hypertension independent of abdominal subcutaneous fat volume and fasting plasma insulin. On the other hand, Foy et al. ${ }^{17}$ reported in the Insulin Resistance Atherosclerosis Study that among African-American and HispanicAmerican men, ASFA, but not IAFA, was significantly associated with the prevalence of hypertension. Our findings of greater visceral adiposity associated with an increased odds of the prevalence of hypertension independent of ASFA and insulin resistance in native Japanese men were consistent with previous reports in Japanese Americans. ${ }^{13,14}$ Differences in body composition by ethnicity might have a key role in explaining the inconsistent results in the literature on the association between intra-abdominal fat and hypertension. Asians and Asian Americans have been reported to have a lower prevalence of obesity by body mass index compared with Caucasians or African Americans but have greater visceral adiposity at the same body mass index or waist circumference level as Caucasians or African Americans. ${ }^{19-21,32,33}$

In this study, ASFA was not associated with an increased odds of the prevalence of hypertension in the models that included both IAFA and insulin resistance. This finding was consistent with previous reports in Japanese Americans. ${ }^{13,14}$ Although Oka et al. ${ }^{18}$ showed in native Japanese that both intra-abdominal fat and ASFA were independently correlated with systolic and diastolic blood pressure, they did not control for confounders such as insulin resistance.

There are several possible mechanisms that may explain the relationship between visceral adipose tissue and prevalence of high blood pressure. This pathophysiological link may be partly mediated by insulin resistance. ${ }^{34-37}$ In this study, as the association between visceral adiposity and hypertension was independent of insulin resistance, visceral adiposity may affect hypertension through mechanisms unrelated to fasting plasma insulin.

Increasing evidence has suggested that adipocyte-derived substances, such as tumor necrosis factor- $\alpha$, plasminogen-activator inhibitor type 1 or adiponectin, are involved in the development of hypertension. ${ }^{38-40}$ Visceral fat has been reported to have a more important role in producing some of these substances than subcutaneous fat. ${ }^{41-43}$ Therefore, adipocyte-derived circulating factors may be involved in part in the pathogenesis of high blood pressure associated with visceral adiposity. The role of visceral adiposity in the pathogenesis of hypertension requires further investigation.

Our study has several limitations. First, we cannot draw conclusions about cause-and-effect relationships because of the cross-sectional nature of our data. Second, we adjusted our analysis for multiple potential confounding variables, including age, fasting immunoreactive insulin, diabetes status, measures of regional and total adiposity, alcohol consumption, regular physical exercise, and smoking habit. However, other unknown or unmeasured confounding variables might explain the relationship of visceral adiposity to high blood pressure for which we did not account. Third, we used a limited single-slice visceral fat area at the umbilicus level to estimate total visceral fat volume. However, this measurement has been reported to have a high correlation with directly ascertained total visceral fat volume. ${ }^{24-26}$ Fourth because we studied a single ethnic group of men, our results may not apply to the general population but may apply to Japanese-American men and also possibly other Asian-American and native Asian men. Fifth, anti-hypertensive medication might have some effect on the association between visceral adiposity and the prevalence of hypertension. However, even if some anti-hypertensive medications decreased visceral fat area, results from our study would underestimate the association between visceral adiposity and the prevalence of hypertension.

In conclusion, these results provide evidence that greater visceral adiposity is associated with an increased odds of high blood pressure in Japanese men. This association is independent of ASFA and insulin resistance. The mechanism by which visceral fat may increase the odds of high blood pressure remains to be determined. Further prospective research is warranted to explore the relationship of visceral fat accumulation to the risk of incident high blood pressure in Japanese.

\section{CONFLICT OF INTEREST}

The authors declare no conflict of interest.

\section{ACKNOWLEDGEMENTS}

This work was supported by a Grant-in-Aid for Scientific Research (17390177, 20390187) from the Ministry of Education, Culture, Sports, Science and Technology, as well as by the facilities and services provided by the Ohtori Health Promotion Center. The funding sources had no role in the decision to submit the paper for publication. We thank the participants in the Ohtori Study for their dedication.

1 Ohlson LO, Larsson B, Svardsudd K, Welin L, Eriksson H, Wilhelmsen L, Björntorp P, Tibblin G. The influence of body-fat distribution on the incidence of diabetes-mellitus: 13.5 years of follow-up of the participants in the study of men born in 1913. Diabetes 1985; 34: 1055-1058.

2 Chan JM, Rimm EB, Colditz GA, Stampfer MJ, Willett WC. Obesity, fat distribution, and weight-gain as risk-factors for clinical diabetes in men. Diabetes Care 1994; 17: 961-969.

3 Cassano PA, Segal MR, Vokonas PS, Weiss ST. Body fat distribution, blood pressure, and hypertension: a prospective cohort study of men in normative aging study. Ann Epidemiol 1990; 1: 33-48.

4 Gillum RF, Mussolino ME, Madans JH. Body fat distribution and hypertension incidence in women and men: the NHANES I Epidemiologic Follow-Up Study. Int J Obes 1998; 22: 127-134.

5 Folsom AR, Prineas RJ, Kaye SA, Munger RG. Incidence of hypertension and stroke in relation to body-fat distribution and other risk-factors in older women. Stroke 1990; 21 : 701-706.

6 Haffner SM, Valdez R, Morales PA, Mitchell BD, Hazuda HP, Stern MP. Greater effect of glycemia on incidence of hypertension in women than in men. Diabetes Care 1992; 15: 1277-1284.

7 Haffner SM, Miettinen H, Gaskill SP, Stern MP. Metabolic precursors of hypertension: the San Antonio Heart Study. Arch Intern Med 1996; 156: 1994-2001. 
8 Rexrode KM, Carey VJ, Hennekens CH, Walters EE, Colditz GA, Stampfer MJ, Willett WC, Manson JE. Abdominal adiposity and coronary heart disease in women. JAMA 1998; 280: 1843-1848.

9 Canoy D, Boekholdt SM, Wareham N, Luben R, Welch A, Bingham S, Buchan I, Day N, Khaw KT. Body fat distribution and risk of coronary heart disease in men and women in the European prospective investigation into cancer and nutrition in Norfolk cohort: a population-based prospective study. Circulation 2007; 116: 2933-2943.

10 Hayashi T, Boyko EJ, McNeely MJ, Leonetti DL, Kahn SE, Fujimoto WY. Visceral adiposity, not abdominal subcutaneous fat area, is associated with an increase in future insulin resistance in Japanese Americans. Diabetes 2008; 57: 1269-1275.

11 Boyko EJ, Fujimoto WY, Leonetti DL, Newell-Morris L. Visceral adiposity and risk of type 2 diabetes: a prospective study among Japanese Americans. Diabetes Care 2000; 23: 465-471.

12 Tong J, Boyko EJ, Utzschneider KM, McNeely MJ, Hayashi T, Carr DB, Wallace TM, Zraika S, Gerchman F, Leonetti DL, Fujimoto WY, Kahn SE. Intra-abdominal fat accumulation predicts the development of the metabolic syndrome in non-diabetic Japanese-Americans. Diabetologia 2007; 50: 1156-1160.

13 Hayashi T, Boyko EJ, Leonetti DL, McNeely MJ, Newell-Morris L, Kahn SE, Fujimoto WY. Visceral adiposity and the prevalence of hypertension in Japanese Americans. Circulation 2003; 108: 1718-1723.

14 Hayashi T, Boyko EJ, Leonetti DL, McNeely MJ, Newell-Morris L, Kahn SE, Fujimoto WY. Visceral adiposity is an independent predictor of incident hypertension in Japanese Americans. Ann Intern Med 2004; 140: 992-1000.

15 Fujimoto WY, Bergstrom RW, Boyko EJ, Chen KW, Leonetti DL, Newell-Morris L, Shofer JB, Wahl PW. Visceral adiposity and incident coronary heart disease in JapaneseAmerican men: the 10-year follow-up results of the Seattle Japanese-American Community Diabetes Study. Diabetes Care 1999; 22: 1808-1812.

16 Fox CS, Massaro JM, Hoffmann U, Pou KM, Maurovich-Horvat P, Liu CY, Vasan RS, Murabito JM, Meigs JB, Cupples LA, D'Agostino Sr RB, O'Donnell CJ. Abdominal visceral and subcutaneous adipose tissue compartments: association with metabolic risk factors in the Framingham Heart Study. Circulation 2007; 116: 39-48.

17 Foy C, Hsu F, Haffner S, Norris J, Rotter J, Henkin L, Bryer-Ash M, Chen YD, Wagenknecht LE. Visceral fat and prevalence of hypertension among African Americans and Hispanic Americans: findings from the IRAS Family Study. Am J Hypertens 2008; 21: 910-916.

18 Oka R, Miura K, Sakurai M, Nakamura K, Yagi K, Miyamoto S, Moriuchi T, Mabuchi H, Koizumi J, Nomura H, Takeda Y, Inazu A, Nohara A, Kawashiri MA, Nagasawa S, Kobayashi J, Yamagishi M. Impacts of visceral adipose tissue and subcutaneous adipose tissue on metabolic risk factors in middle-aged Japanese. Obesity 2010; 18 : 153-160.

19 McNeely MJ, Boyko EJ. Type 2 diabetes prevalence in Asian Americans. Diabetes Care 2004; 27: 66-69.

20 Wang J, Thornton JC, Russell M, Burastero S, Heymsfield S, Pierson RN. Asians have lower body mass index but higher percent body fat than do whites: comparisons of anthropometric measurements. Am J Clin Nutr 1994; 60: 23-28.

21 Araneta MR, Barrett-Connor E. Ethnic differences in visceral adipose tissue and type 2 diabetes: Filipino, African-American, and white women. Obes Res 2005; 13: 1458-1465.

22 Matthews DR, Hosker JP, Rudenski AS, Naylor BA, Treacher DF, Turner RC. Homeostasis model assessment: insulin resistance and beta-cell function from fasting plasma glucose and insulin concentrations in man. Diabetologia 1985; 28: 412-419.

23 Pate RR, Pratt M, Blair SN, Haskell WL, Macera CA, Bouchard C, Buchner D, Ettinger W, Heath GW, King AC, Kriska A, Leon AS, Marcus BH, Morris J, Paffenbarger RS, Patrick K, Pollock ML, Rippe JM, Sallis J, Wilmore JH. Physical activity and public health: a recommendation from the Centers for Disease Control and Prevention and the American College of Sports Medicine. JAMA 1995; 273: 402-407.

24 Schoen RE, Thaete FL, Sankey SS, Weissfeld JL, Kuller LH. Sagittal diameter in comparison with single slice CT as a predictor of total visceral adipose tissue volume. Int J Obes 1998; 22: 338-342.

25 Han TS, Kelly IE, Walsh K, Greene RME, Lean MEJ. Relationship between volumes and areas from single transverse scans of intra-abdominal fat measured by magnetic resonance imaging. Int J Obes 1997; 21: 1161-1166.
26 Shen W, Punyanitya M, Wang ZM, Gallagher D, St-Onge MP, Albu J, Heymsfield SB, Heshka S. Visceral adipose tissue: relations between single-slice areas and total volume. Am J Clin Nutr 2004; 80: 271-278.

27 McNeely MJ, Shofer JB, Schwartz RS, Leonetti DL, Boyko EJ, Newell-Morris L, Kahn SE, Fujimoto WY. Use of computed tomography regional fat areas to estimate adiposity: correlation with hydrodensitometry, bioelectrical impedence, skinfold thickness, and body mass index. Obes Res 1999; 7(Suppl 1): 47S.

28 Chalmers J, MacMahon S, Mancia G, Whitworth J, Beilin L, Hansson L, Neal B, Rodgers A, Mhurchu CN, Clark T, Guidelines Subcommittee of the WHO-ISH. 1999 World Health Organization-International Society of Hypertension guidelines for the management of hypertension. J Hypertens 1999; 17: 151-183.

29 Gavin JR, Alberti K, Davidson MB, DeFronzo RA, Drash A, Gabbe SG, Genuth S, Harris MI, Kahn R, Keen H, Knowler WC, Lebovitz H, Maclaren NK, Palmer JP, Raskin P, Rizza RA, Stern MP. Report of the expert committee on the diagnosis and classification of diabetes mellitus. Diabetes Care 1997; 20: 1183-1197.

30 Menard SW. Applied Logistic Regression Analysis, 2nd edn. Sage Pubulication: California, 2001, pp 75-78.

31 Boyko EJ, Leonetti DL, Bergstrom RW, Newell-Morris L, Fujimoto WY. Visceral adiposity, fasting plasma insulin, and blood pressure in Japanese-Americans. Diabetes Care 1995; 18: 174-181.

32 Kadowaki T, Sekikawa A, Murata K, Maegawa H, Takamiya T, Okamura T, El-Saed A, Miyamatsu N, Edmundowicz D, Kita Y, Sutton-Tyrrell K, Kuller LH, Ueshima H. Japanese men have larger areas of visceral adipose tissue than Caucasian men in the same levels of waist circumference in a population-based study. Int J Obes 2006; 30: 1163-1165.

33 Carroll JF, Chiapa AL, Rodriquez M, Phelps DR, Cardarelli KM, Vishwanatha JK, Bae S, Cardarelli R. Visceral fat, waist circumference, and BMI: impact of race/ethnicity. Obesity 2008; 16: 600-607.

34 Landsberg L. Insulin-mediated sympathetic stimulation: role in the pathogenesis of obesity-related hypertension (or, how insulin affects blood pressure, and why). J Hypertens 2001; 19: 523-528.

35 Gupta A, Clark R, Kirchner K. Effects of insulin on renal sodium excretion. Hypertension 1992; 19(1 Suppl): I78-182.

36 Anderson EA, Hoffman RP, Balon TW, Sinkey CA, Mark AL. Hyperinsulinemia produces both sympathetic neural activation and vasodilation in normal humans. J Clin Invest 1991; 87: 2246-2252.

37 Cardillo C, Nambi SS, Kilcoyne CM, Choucair WK, Katz A, Quon MJ, Panza JA. Insulin stimulates both endothelin and nitric oxide activity in the human forearm. Circulation 1999; 100: 820-825.

38 Wajchenberg BL. Subcutaneous and visceral adipose tissue: their relation to the metabolic syndrome. Endocr Rev 2000; 21: 697-738.

39 Kazumi T, Kawaguchi A, Sakai K, Hirano T, Yoshino G. Young men with high-normal blood pressure have lower serum adiponectin, smaller LDL size, and higher elevated heart rate than those with optimal blood pressure. Diabetes Care 2002; 25: 971-976.

40 Iwashima Y, Katsuya T, Ishikawa K, Ouchi N, Ohishi M, Sugimoto K, Fu Y, Motone M, Yamamoto K, Matsuo A, Ohashi K, Kihara S, Funahashi T, Rakugi H, Matsuzawa Y, Ogihara T. Hypoadiponectinemia is an independent risk factor for hypertension. Hypertension 2004; 43: 1318-1323.

41 Shimomura I, Funahashi T, Takahashi M, Maeda K, Kotani K, Nakamura T, Yamashita S, Miura M, Fukuda Y, Takemura K, Tokunaga K, Matsuzawa Y. Enhanced expression of PAI-1 in visceral fat: possible contributor to vascular disease in obesity. Nat Med 1996; 2: 800-803.

42 Alessi MC, Peiretti F, Morange P, Henry M, Nalbone G, Juhan-Vague I. Production of plasminogen activator inhibitor 1 by human adipose tissue: possible link between visceral fat accumulation and vascular disease. Diabetes 1997; 46: 860-867.

43 Motoshima H, Wu X, Sinha MK, Hardy VE, Rosato EL, Barbot DJ, Rosato FE, Goldstein BJ. Differential regulation of adiponectin secretion from cultured human omental and subcutaneous adipocytes: effects of insulin and rosiglitazone. J Clin Endocrinol Metab 2002; 87: 5662-5667. 